\title{
Optimization Analysis on Electrical Insulation Performance of ITER Axial Composite Insulation Break
}

\author{
Yun-Lai QIU ${ }^{1, a}$, Chang-Chun YANG ${ }^{2, b}$ \\ ${ }^{1,2}$ College of Electric Engineering, Jiujiang University, China 332005 \\ a1366921530@qq.com, b395254993@qq.com
}

Keywords: Optimization Analysis, Electrical Insulation Performance, ITER, Insulation Break (IB).

\begin{abstract}
Optimization analysis on Electrical Insulation Performance was conducted using ANSYS soft for ITER axial insulation breaks. The optimal parameters of $\mathrm{Li}$, and $\mathrm{R}$ have been achieved. The analysis results showed that the value of the maximal electric field in GFRP section is $3.396 \mathrm{kV} / \mathrm{mm}$. This position locates on the arc top of the interface between SS electrode and GFRP section. The field strength is respectively less than allowable $4 \mathrm{kV} / \mathrm{mm}$ and $2 \mathrm{kV} / \mathrm{mm}$ in GFRP and in air to meet the technical requirements of ITER axial insulation breaks.
\end{abstract}

\section{Introduction}

Low-temperature high-pressure Helium tightness axial composite insulation breaks are key components of ITER (International Thermal nuclear fusion Experimental Reactor) magnet systems [1]. The outer surface has a metal screen which is integrated into the ground screen of the high voltage cryogenic line, and there is metal reinforcing of both the insulating part, particularly where it overlaps the steel tubes to form a bond [2]. There length must be sufficient to prevent electrical breakdown between the two steel tubes through the fluid or gas. During the assembly and operation of the apparatus the cold shrink generated thermal stress, due to the large superconducting magnet and the return temperature of the cooling process, and the electromagnetic interaction generated tensile stress during charging and discharging, then causing damage hermetic insulation, which led to the cryogenic liquid into the vacuum system, prone to PASCHEN discharge, the entire apparatus will have a devastating damage [3]. Fig.1 shows a sketch of a preliminary design for the ITER insulating break component before assembly.

These conditions correspond to (1)Maximum operating voltage level (PF coils) of 15kV DC; (2)Maximum voltage level in fault conditions (PF coils) of $28 \mathrm{kV} \mathrm{DC}$; (3)Helium gas in Paschen conditions on the outside of the $4.5 \mathrm{~K} \mathrm{IBs}$ and air for the $300 \mathrm{~K} \mathrm{IBs}$.In order to get equivalent dielectric strength as air, sufficiently high to possibly allow the execution of dielectric tests of the assembled ITER coils, design breakdown voltage side-side in dry air or pressurized helium of the axial insulation break higher than 2 times the maximum voltage level in fault condition i.e. $>56 \mathrm{kV}$.

The IBs are assembled in air or helium circumstances. Because the breakdown strength of in GFRP and in air is generally $20 \sim 30 \mathrm{kV} / \mathrm{mm}$ and $10 \mathrm{kV} / \mathrm{mm}$ respectively, the allowable electric field in GFRP and in air should be less than $4 \mathrm{kV} / \mathrm{mm}$ and $2 \mathrm{kV} / \mathrm{mm}$ respectively if the safety factor is 5 .

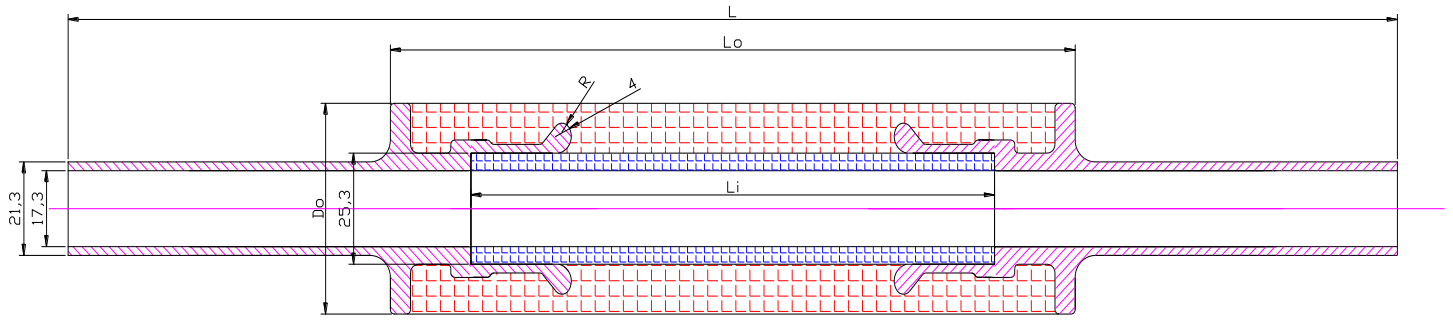

Fig.1.Cross section parameters of ITER axial IB design 


\section{Optimization Design}

In the electrical design analysis, the simplified assumptions are made as follows: (1) Inner diameter and Outer diameter of geometric parameters for stainless steel pipes are respectively $17.3 \mathrm{~mm}$ and $21.3 \mathrm{~mm}$. (2) Relative permittivity of GFRP can be designed as 2.5. This is based on volume content of epoxy-resin adhesive and fiberglass. and Relative permittivity of air circumstance as well as vacuum is 1.0. Optimized parameters $\mathrm{Li}, \mathrm{R}$.

The pipe's ends were shaped to reduce the electric field strength in the material and on the boundary surfaces for avoiding slide discharges. The electrical and mechanical properties were analyzed using ANSYS [6]. Preliminary design parameters are listed in Table 1.

Tab. 1.Optimizing design parameters $[7,8]$

\begin{tabular}{lll}
\hline No. & $\mathrm{R}(\mathrm{mm})$ & $\mathrm{Li}(\mathrm{mm})$ \\
\hline 1 & 1 & 90 \\
2 & 1.5 & 120 \\
3 & 2 & 130 \\
\hline 4 & 2.5 & 150 \\
\hline
\end{tabular}

\section{Electrical Design Analysis}

ITER axial insulation break is shown in figure 1. Optimized design parameters are listed in table 2. The following simplified assumptions were made in the electrical design analysis.

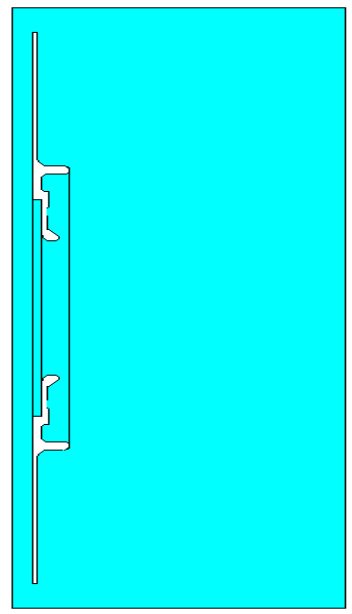

(a)

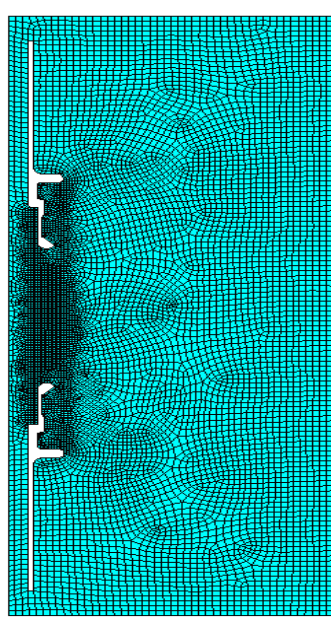

(b)

Fig. 2.The model and mesh for the electrical design analysis

1. Relative permittivity of GFRP can be designed as 2.5-5.5. This is based on volume content of epoxy-resin adhesive and fiberglass. In this analysis, Relative permittivity of GFRP is 2.5 .

2. Figure 2. Shows the model and mesh.

3. Design breakdown voltage side-side in dry air or pressurized helium higher than 2 times the maximum voltage level in fault condition i.e. $>56 \mathrm{kV}$.

4. Preliminary parameters $\mathrm{L}=330 \mathrm{~mm}, \mathrm{Lo}=160 \mathrm{~mm}, \mathrm{Li}=120 \mathrm{~mm}, \mathrm{R}=2 \mathrm{~mm}, \theta=131^{\circ}, \mathrm{Do}=51.3 \mathrm{~mm}$.

\section{Parameter $R(L=330 \mathrm{~mm}, \mathrm{Li}=130 \mathrm{~mm}, \mathrm{R}=2 \mathrm{~mm}, \mathrm{gr}=2.5, \mathrm{Do}=48 \mathrm{~mm}$. $)$}

The tube's ends were shaped to reduce the electric field strength in the material and on the boundary surfaces for avoiding slide discharges. 


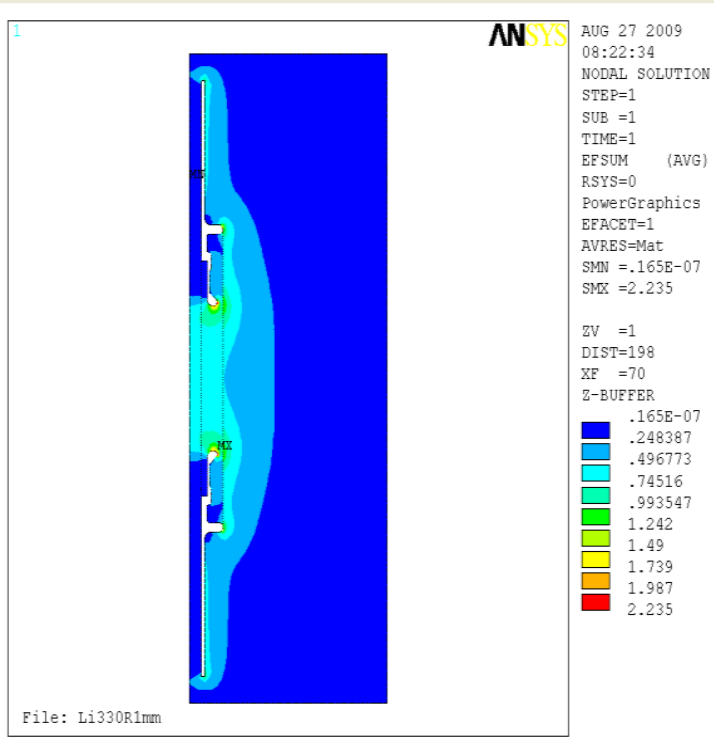

(a)

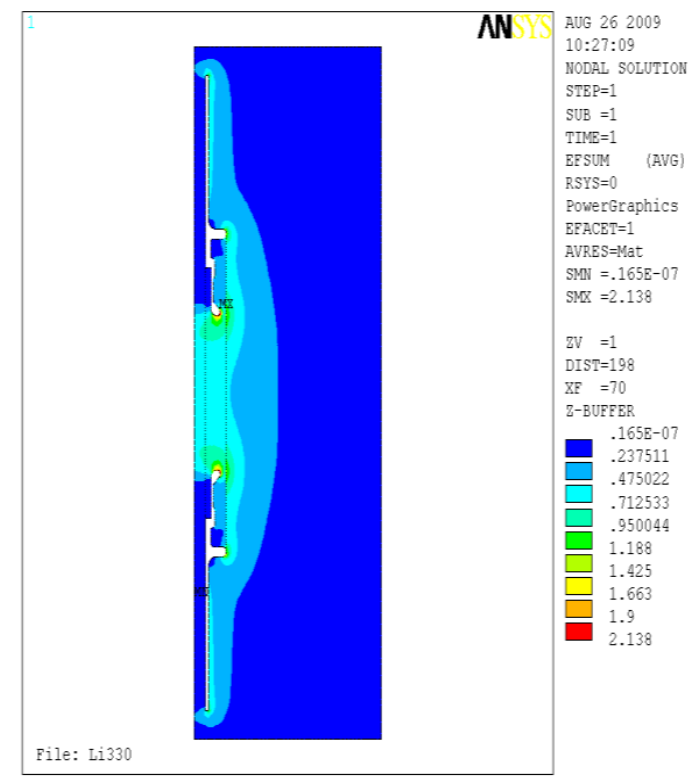

(c)

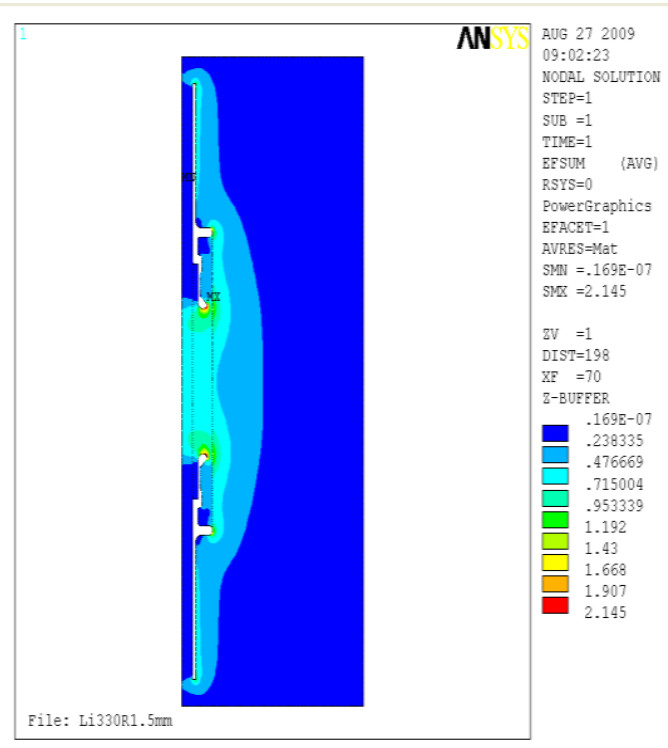

(b)

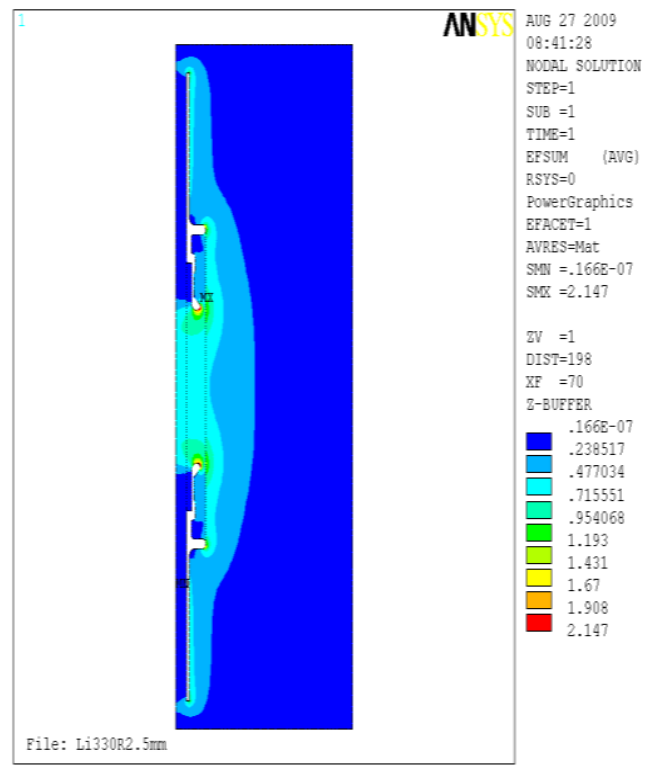

(d)

Fig. 3.The electric field of the IBs due to difference of $R[(a) R=1 \mathrm{~mm},(b) R=1.5 \mathrm{~mm},(c) R=2 \mathrm{~mm}$, $(\mathrm{d}) \mathrm{R}=2.5 \mathrm{~mm}]$

According to the electrical design analysis due to difference of R, In figure 3.(a),(b),(c)and(d),It shows the value of the maximum electric field is smallest $2.138 \mathrm{kV} / \mathrm{mm}$ when the value of $\mathrm{R}$ is $2 \mathrm{~mm}$. So we consider that the optimal parameter of $\mathrm{R}$ is $2 \mathrm{~mm}$.

\section{Parameter Li( $L=330 \mathrm{~mm}$, Do=48mm, $R=2 \mathrm{~mm}$, $\varepsilon r=2.5$ )}

This length ensures a dielectric insulation along the inner pipe interface between high voltage and low voltage parts. During operation, being the interface between resin and liquid helium, a spacing of several millimeters may already provide the required dielectric insulation. However, the need for testing the dielectric integrity of the ITER coils during installation and operation requires increasing this distance to withstand test levels up to $29 \mathrm{kV}$ in air or pressured helium to guarantee that there is no flash over between $\mathrm{HV}$ and LV pipe sections.

In order to ensure safety, we recommend adopting a design voltage of $56 \mathrm{kV}$ in dry air, with some margin and considering the interface with the interface of the external insulation wrap. 


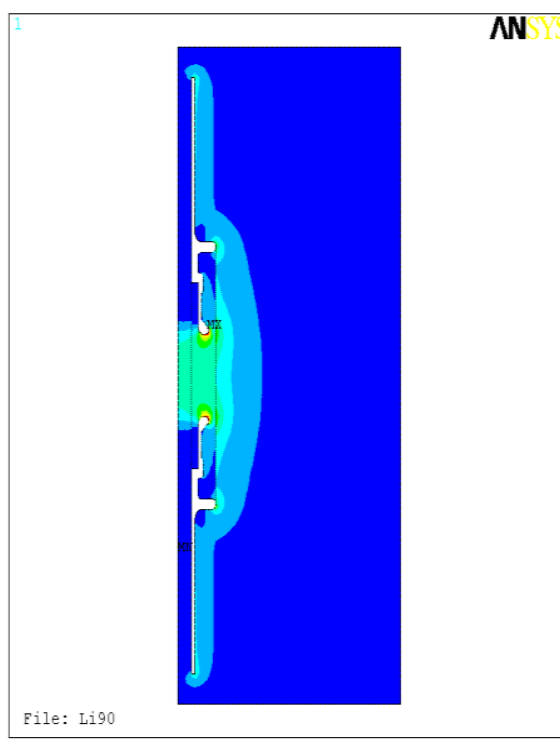

(a)

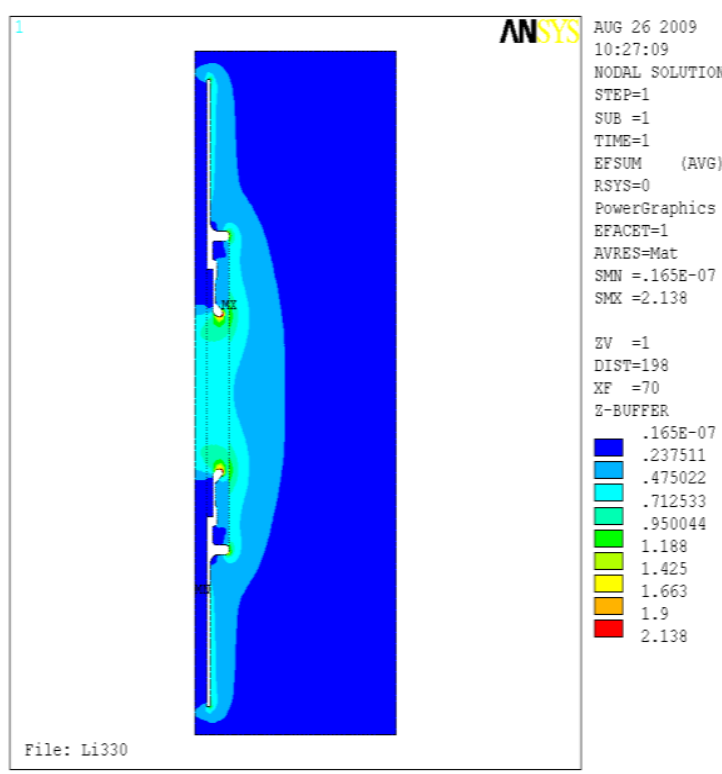

(c)

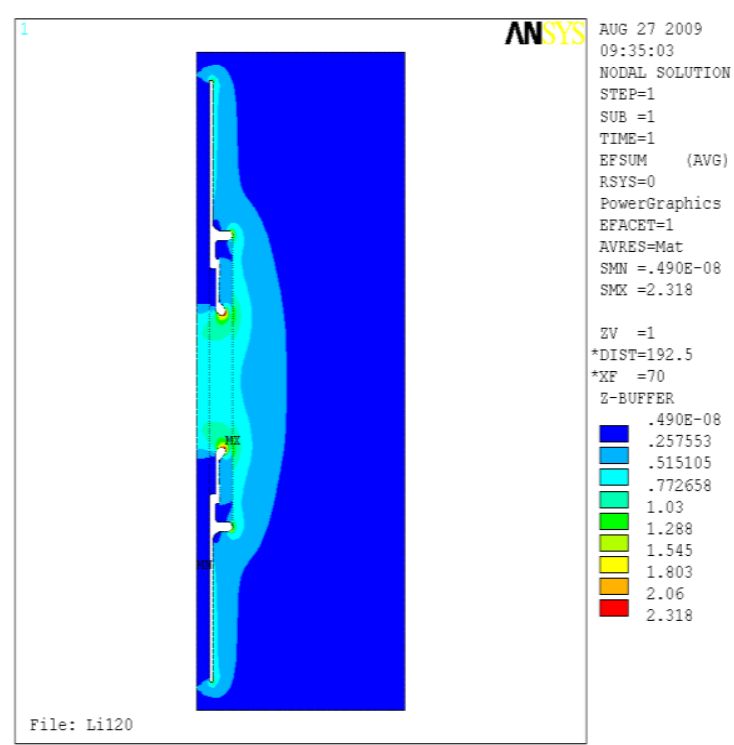

(b)

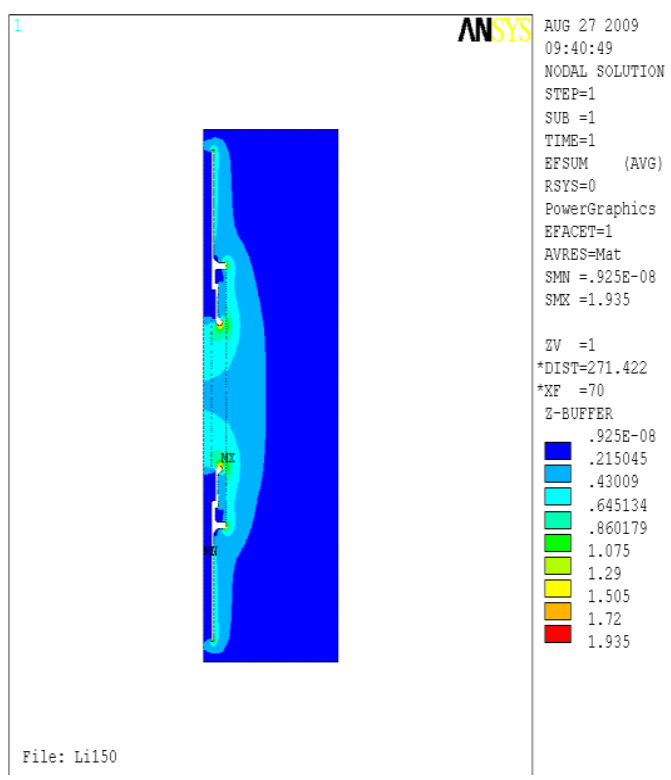

(d)

Fig. 5.The of the IBs due to difference of $\mathrm{Li}[$ (a) $\mathrm{Li}=90 \mathrm{~mm}$, (b) $\mathrm{Li}=120 \mathrm{~mm}$, (c) $\mathrm{Li}=130 \mathrm{~mm}$, (d) $\mathrm{Li}=150 \mathrm{~mm}]$

Comparing the above four results in figure 5, it is clear that the value of the electric field along the inner pipe interface between high voltage and low voltage parts is not more than $1 \mathrm{kV} / \mathrm{mm}$ when the length of the parameter $\mathrm{Li}$ is equal to $130 \mathrm{~mm}$, at the same time the value of the maximal electric field strength is $2.138 \mathrm{kV} / \mathrm{mm}$. So we recommend adopting a optimal design parameter $\mathrm{Li}=130 \mathrm{~mm}$.

\section{Conclusion}

The electrical design analysis was conducted using the finite element method. An electrical properties design parameters model was optimized and analyzed. The results as follows:(1) the optimal parameters $\mathrm{Li}=130 \mathrm{~mm}, \mathrm{R}=2 \mathrm{~mm}$, have been achieved. (2) The field strength of the axial break along the interface inner pipe is less than $1 \mathrm{kV} / \mathrm{mm}$,i.e.safe field strength in dry air.(3) The maximal field strength of the IBs for the optimal design parameters located on the top end of SS316LN electrodes, the value of the maximum field strength is equal to $1.977 \mathrm{kV} / \mathrm{mm}<2 \mathrm{kV} / \mathrm{mm}$ 


\section{Acknowledgements}

The research work was supported by National Natural Science Foundation of China under Grant No. 51107138 .

\section{References}

[1] Yang Changchun. Experiment research on low-temperature mechanic fatigue performance of ITER axial insulation breaks. Cryogenic \& Superconductivity, 39(11), pp.7-10, 2011.

[2] Yang Changchun Pan Wanjiang. Design and analysis on ITER axial insulation breaks. Nuclear Fusion and Plasma Physics, 30(3), pp.272-276, 2010.

[3] Wu Cheng, Pan Wanjiang, Yang Changchun. Research on performance test of ITER composite axial insulation breaks. Cryogenic \& Superconductivity, 39(10), pp.12-16. 2011.

[4] Zhang Yuanbin, Pan Wanjiang, Xi Weibin, Study of the property of EAST composite insulators with finite element analysis[J]. Nuclear Fusion and Plasma Physics, 27(2), pp.137-140, 2007

[5] Zhang Yuanbin, Pan Wanjiang. Theoretical and experimental analysis of cryogenic mechanics property for EAST Tokamak composite insulators [J]. Atomic Energy Science and Technology, 41(6), pp.752-755, 2007.

[6]Yang Changchun Pan Wanjiang Wu Songtao. Test research on the performance of EAST composite axial insulation breaks. Cryogenics, (4), pp.23-27, 2009. 